- Dental teams could contribute to meeting Government targets for reducing coronary heart disease and cancer.

- Dentists' views on involvement in general health promotion were influenced by whether they saw the purpose of dentistry as achieving health or treating disease. Those with more of a health focus were already involved and wanted to do more.

- Dental teams' involvement in general health promotion is lower than might be expected given reported views on its relevance to dentistry.

- Although barriers to involvement included time and financial factors, current workload and lack of personal skills, fewer dentists felt that these were barriers for PCDs.

\title{
General health promotion in general dental practice - The involvement of the dental team Part 2: A qualitative and quantitative investigation of the views of practice principals in South Yorkshire
}

\author{
T. A. Dyer ${ }^{1}$ and P. G. Robinson ${ }^{2}$
}

Aim To investigate the factors that might influence the provision of general health promotion through seven different health interventions by dental teams in general dental practice.

Method A mixed-method was used comprising cross-sectional qualitative research using semi-structured interviews of a purposive sample of 10 practice principals, and a cross sectional survey of a practice principal from every dental practice in South Yorkshire, using a selfcomplete questionnaire.

Results Two core categories emerged from the qualitative data: seeing health or disease and practitioners' views of the structure of dental practice. The former refers to the participants' general outlook and cut across many dimensions constituting the structure of dental practice. Health-orientated dentists were more likely to be involved in prevention and were more open-minded to expanding the dental team's role into general health promotion. However participants perceived that barriers existed to involvement such as time and financial factors, current workload and lack of personal skills. The response rate of useable questionnaires in the cross sectional survey was 84\%. Reported levels of involvement in general health promotion were low. Most frequently reported barriers were 'insufficient funding' and 'poor use of time'. 'Poor use of time' and 'lack of training/knowledge' were reported less frequently for professionals complementary to dentistry (PCDs) than

The term Professionals Complementary to Dentistry (PCDs) has been retained in this report as this was the accepted term for Dental Care Professionals at the time of data collection and when the paper was accepted for publication

\footnotetext{
1*Specialist Registrar in Dental Public Health, Directorate of Public Health, Rotherham and Barnsley Primary Care Trusts, Bevan House, Oakwood Hall Drive, Rotherham, S60 3AO 2 Professor of Dental Public Health, Department of Oral Health and Development, School of Clinical Dentistry, University of Sheffield, Claremont Crescent, Sheffield, S10 2TA;

${ }^{*}$ Correspondence to: Mr Tom Dyer

Email: t.dyer@sheffield.ac.uk
}

\section{Refereed paper}

Accepted 16 June 2005

DOI: $10.1038 /$ sj.bdj.4813774

() British Dental Journal 2006; 201: 45-51 dentists $(p<0.05)$. Most dentists agreed that PCDs could be trained to deliver health interventions and would be happy for PCDs to do so in their practice if reported barriers were removed.

Conclusions Although dental teams' involvement in general health promotion is low, there is willingness to increase involvement, particularly among health-orientated dentists. Some reported barriers to involvement might be removed by impending changes to the GDS in England. Other important factors include a lack of education and workforce shortages of dentists and PCDs. Respondents indicated a high regard for PCDs and there was broad agreement that they were suitable to be involved in this work.

\section{INTRODUCTION}

The Government intends to improve the health of the population by reducing the risk factors for cancer and circulatory disease (coronary heart disease and stroke) as described in Saving lives: Our healthier nation. ${ }^{1}$ In England Modernising NHS dentistry: Implementing the plan ${ }^{2}$ and Options for change ${ }^{3}$ complemented this strategy. Both suggested that dental teams should be involved in smoking cessation and one emphasised the importance of preventing alcohol misuse for oral and general health benefit. $^{2}$ Adopting this strategy would broaden the public health role for dental teams through a common risk factor approach ${ }^{3,4}$ and might contribute to the targets set in Saving lives: Our healthier nation. ${ }^{1}$ It would also be commensurate with measures described on public health delivery in the Wanless Report ${ }^{6}$ and Choosing health. ${ }^{7}$

Our earlier study ${ }^{8}$ found that healthcare workers can be effective in seven different health interventions that might have an effect on cancer and circulatory disease prevalence; however, there was limited evidence of effectiveness of dentists and their teams. Quantitative research has investigated the views of dentists on their involvement in smoking cessation, ${ }^{9-11}$ on reducing risk factors for oral cancer, including excessive alcohol consumption ${ }^{12,13}$ and involvement in routine blood pressure monitoring for patients. ${ }^{14}$ However there are no data on the prevention of 
smoking, dietary counselling, advice on physical exercise and skin cancer prevention.

Studies investigating dentists' views on smoking cessation and on inquiring about alcohol consumption have found similar trends. Early ${ }^{9,10}$ and more recent studies ${ }^{11}$ found that the percentage of dentists involved in smoking cessation was considerably lower than those who felt they had a role to play in such activity. However, involvement is increasing. ${ }^{11}$ Similarly, although most dentists identified alcohol as a risk factor for oral cancer, ${ }^{12}$ very few routinely inquired about consumption levels. ${ }^{12,13}$ Frequently reported barriers to being involved in smoking cessation include pressures of time and finance. ${ }^{9,13,14}$ Lack of training and possible adverse effects on the dentist-patient relationship have been identified as barriers for both smoking cessation ${ }^{9,10,14}$ and inquiring on alcohol consumption. ${ }^{12}$

A similar trend has been reported for involvement in blood pressure monitoring. While only 5\% of dentists routinely measured blood pressure, more than a quarter of respondents thought it was a good idea. Suggested barriers to involvement included a lack of remuneration, clear professional demarcation between the roles of medicine and dentistry in the UK and concerns over the suitability of dental practice surroundings, particularly if patients are anxious. ${ }^{15}$

The importance of a team approach to smoking cessation in dental practice has been repeatedly emphasised, ${ }^{16-23}$ which logically could be applied to all preventive health interventions. In North America, PCDs already have a significant role in smoking cessation, ${ }^{24,25}$ general diet counselling ${ }^{26-28}$ and, to a lesser extent, alcohol consumption advice. ${ }^{29,30}$ A Medline search did not identify any comparable UK data.

If dental teams are to contribute to Government public health targets in cancer and circulatory disease, it is essential to learn more about how dentists feel about this work. Therefore the aim of this study is to investigate the factors that might influence dental teams' involvement in general health promotion by exploring dentists' views on:

- General health promotion through preventive health interventions; and

- Dental teams' involvement in this work.

And by describing dentists':

- Level of involvement in 7 different public health interventions;

- Views of the relevance of these interventions to their work;

- Views of dentists' and PCDs' involvement in these interventions, including any perceived barriers to such activity.

\section{METHOD}

A mixed-method approach was adopted. Qualitative methods suit topics such as this where there is little pre-existing knowledge. ${ }^{31}$ However qualitative research cannot make quantifiable generalisations so a cross-sectional survey of dentists was also undertaken.

\section{Qualitative method}

Qualitative semi-structured interviews were used to allow exploration of principal dentists' attitudes toward their dental teams' involvement in oral and general health promotion and their reported behaviour in such activity.

Purposive sampling of principal dentists ensured a full range of perspectives was included in the study. Time since qualification $^{9-11}$ and the NHS/private mix of a practice ${ }^{10,11}$ both influence perspectives of involvement in general health promotion in quantitative studies. Other factors such as dentists' sex and practice size were also assumed to be influential variables. Ten potential participants were selected from the four health communities in South Yorkshire.

Interviews were audiotaped and transcribed as fully as possible. A synopsis of each interview, together with a full transcript, was

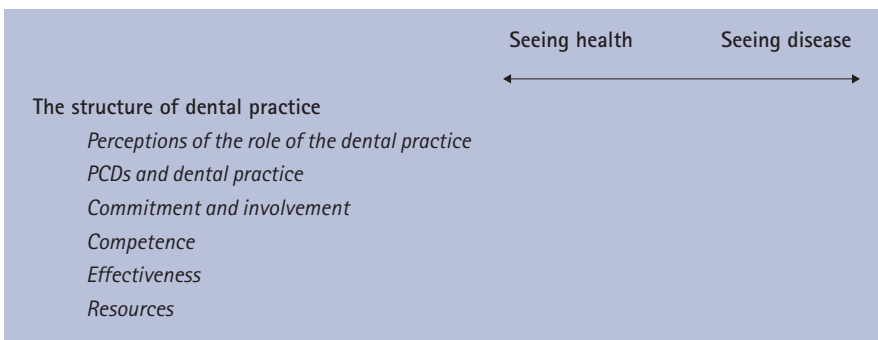

Fig. 1 Framework of factors related to health promotion activity in general dental practice

sent to the relevant participant who was invited to make comments if they were at odds with their intended meaning. No modifications were requested.

Content analysis was used to identify codes and categorise the primary pattern in the data. This analysis was informed by the aims of the study and as such asked three broad questions. Firstly, it asked what the data suggest about the range of dentists' views of general health promotion through public health interventions. Secondly, what they suggest about the range of dentists' views of the dental team's involvement in this activity; and lastly whether any variation in views can be adequately conceptualised. The data were analysed by reading each transcript and coding areas of interest on index cards. ${ }^{33,34}$ From these codes, categories were formed and added to as each transcript was analysed. A detailed descriptive account of emergent theory was then produced which was independently checked by another researcher (PGR). The data are presented below within major themes that emerged from the analysis with quotations to illustrate the findings and allow the reader to judge interpretation.

\section{Quantitative method}

A self-administered questionnaire was sent to a principal dentist at all 199 dental practices in South Yorkshire. Closed questions were developed using data from the literature review and the qualitative data. ${ }^{35}$ The questionnaire was then piloted in two stages but required minimal modification.

One principal was selected from each practice using random number tables. A letter of notification was sent to all recipients two weeks before distribution of the questionnaire informing them of the study. Questionnaires were mailed with a covering letter and postage-paid envelope and were coded so that non-responders could be re-mailed. Mailing was in three stages, between April 2003 and July 2003, to maximise the response rate. ${ }^{36,37}$

Areas of enquiry included: practice details; views of the relevance of health interventions to their practice; levels of, and barriers to, involvement in health interventions for both dentists and PCDs; whether respondents would be happy for suitably trained PCDs to deliver health interventions in their practice. The health interventions inquired on were: prevention of smoking/tobacco use; smoking cessation; advice on alcohol consumption; advice on diet and calorie intake; advice on prevention of skin cancer; advice on physical exercise; blood pressure monitoring.

Questionnaires with responses to less than 90\% of items were excluded from the analysis. Where single items were missing, the respondent was excluded from the analysis for that item. Any question answered by less than 90\% respondents was also excluded. Data were analysed in two stages. First, the distribution of variables was described, including a comparison of data from the second and third mailings to consider the effects of non-response bias. Secondly McNemar tests were used to assess whether dentists perceived the barriers were different for themselves and PCDs. The threshold for statistical significance adopted was at the $p<0.05$ level.

All research ethics committees and all PCTs in South Yorkshire granted approval for the study. 


\section{QUALITATIVE RESULTS}

The qualitative data could be arranged on a conceptual framework based on two core categories: Seeing health or disease and The structure of dental practice (Fig. 1)

Seeing health or disease refers to the general outlook of the participant, ie whether they saw striving to achieve health or treating disease as the purpose of dentistry. The structure of dental practice refers to the participant's perception of six structural elements of a dental practice (Fig. 1). Seeing health or disease was found to cut across many of the dimensions within this major category, resulting in a spectrum of views within each.

\section{Seeing health or disease}

Dentists' views could be arranged on a spectrum according to the degree to which their outlook was disease or health-focused. Disease-focused individuals tended toward the traditional biomedical viewpoint, implicitly defining heath as the absence of disease and emphasising 'curative' treatments. Health-focused participants had a more holistic view and emphasised prevention rather than treatment. These views were reflected across several dimensions. Those with a health focus often expressed recognition of the changing role of dentistry:

'I see patients as a whole, I don't see them as teeth and gums - I see patients as real people; it's their general health we are looking after.' (Lance, 19.02.03)

Others had a narrower view of the dentist's remit.

'I think it [health interventions] is outside the remit of dentistry.' (Laurence 18.12.02)

Where the more disease-focused dentists did describe any involvement, it tended to be centred on the mouth. For instance, smoking cessation advice might be given because of staining on patients' teeth or mucosal changes rather than for broader health promoting reasons.

\section{The structure of dental practice}

Participants' views on the structural elements of dental practice fitted into six dimensions (Fig. 1), each of which is illustrated below.

\section{Perceptions of the role of the dental practice}

This dimension refers to the remit of dental practice as perceived by the participant or the perceptions they thought their patients held.

Often the health-focused dentists felt that dental practices' role could include health interventions:

'Patients come and listen to us, they come regularly, they respect us and I think any advice we give them, they listen to us.' (Lance, 19.02.03)

There were however strong views at the other end of the spectrum:

'If patients are really nervous will they really want to talk about how many [alcoholic] drinks they had last night? - I think it would be really difficult.' (Kevin, 17.02.03)

Views of the relevance of particular public health interventions to dental practice varied considerably. Generally participants felt smoking cessation was relevant to dental practice, whereas there were diverse views on blood pressure monitoring.

There was recognition by many of the duty of care towards their patients' general as well as their oral health. On the whole participants felt the medical profession would welcome this expansion of dental practices' role but many recognised that limited integration into the NHS was a barrier to this.
While dentists were uncertain about the views of patients, more positive views were often expressed by the more health-focused, for example:

'Patients are surprised and quite pleased that we are taking an interest in their general health.' (Deborah, 12.12.02)

However, very different perceptions were expressed by both health and disease-orientated dentists:

'I think a practice that starts delving into what a patient considers their own business is running the risk of sending his patients elsewhere.' (Laurence, 18.12.02)

\section{PCDs and dental practice}

There was broad agreement that a team approach will become more important in dental practice, especially if health interventions are to be undertaken, but participants recognised that not all dentists held this view:

'There is a fair proportion of dentists who think that dentists do dentistry and that's it.' (John, 28.11.02)

Where hygienists had been introduced, many experienced some initial resistance by patients to their acceptance, which was subsequently overcome:

'We introduced hygienists several years ago into the practice with some difficulty initially. They were somewhat resistant to someone else doing an item of work..... However, we persevered and now patients request appointments with the hygienists.' (Diane, 21.02.03)

An interesting observation was that only one participant routinely included dental nurses when referring to PCDs. The others only discussed hygienists and therapists and occasionally oral health educators.

\section{Commitment and involvement}

All participants were already involved in health interventions. However involvement beyond smoking cessation and dietary advice varied considerably. Many health-focused participants would have liked to undertake more oral disease prevention. Others, with a more disease focus, expressed reticence and tended to get little enjoyment from preventive dentistry:

'There is not much pleasure to be gained out of oral hygiene instruction in my experience ... I just don't think I would enjoy it [health interventions] really.' (Kevin, 17.02.03)

Many felt that enthusiastic leadership would be the key:

'A lead dentist who is motivated or a practice manager who is an advocate for health promotion.' (Steven, 28.11.02)

'If we were given a directive [laughs] that would help things ... Because I think that a dentist would respond to someone saying this is what you should be doing.' (Diane, 21.02.03)

Views on commitment and involvement of PCDs varied. Participants were keen to delegate preventive work to PCDs whether related to oral or general health. Some were motivated by enthusiasm:

'Initially very, very positive...fantastic, that's my initial thought.' (Isabelle, 12.02.03)

Whereas others merely wanted to pass on unrewarding tasks.

Some health-focused dentists even saw a change in role of the dental practice to include a peripatetic type role for health education delivered by PCDs to nursing homes and schools for example.

However, some had more negative views of the role of PCDs and health interventions, typified by this medicalised view of prevention: 


\begin{tabular}{|c|c|c|c|c|}
\hline & $\begin{array}{l}\text { Never } \\
\%\end{array}$ & $\begin{array}{l}\text { Occasionally } \\
\%\end{array}$ & $\begin{array}{l}\text { Often } \\
\%\end{array}$ & $\begin{array}{l}\text { Everyday } \\
\%\end{array}$ \\
\hline $\begin{array}{l}\text { Prevention of } \\
\text { smoking/tobacco } \\
\text { use } \\
(n=164)\end{array}$ & 14.6 & 53.7 & 22.6 & 9.1 \\
\hline $\begin{array}{l}\text { Smoking } \\
\text { cessation advice } \\
(n=164)\end{array}$ & 13.4 & 53.0 & 23.8 & 9.8 \\
\hline $\begin{array}{l}\text { Advice on } \\
\text { alcohol } \\
\text { consumption } \\
(n=164)\end{array}$ & 39.6 & 48.8 & 8.5 & 3.1 \\
\hline $\begin{array}{l}\text { Advice on diet/ } \\
\text { calorie intake } \\
(n=163)\end{array}$ & 19.0 & 31.3 & 30.1 & 19.6 \\
\hline $\begin{array}{l}\text { Advice on } \\
\text { prevention of } \\
\text { skin cancer } \\
(n=164)\end{array}$ & 54.3 & 39.6 & 6.1 & 0 \\
\hline $\begin{array}{l}\text { Advice on } \\
\text { physical exercise } \\
(n=164)\end{array}$ & 75.6 & 23.8 & 0.6 & 0 \\
\hline $\begin{array}{l}\text { Blood pressure } \\
\text { monitoring } \\
(n=164)\end{array}$ & 72.6 & 23.2 & 3.6 & 0.6 \\
\hline
\end{tabular}

'If it requires medical background knowledge then the hygienists shouldn't be doing it anyway.' (Laurence, 18.12.02)

Another disease-orientated perspective assumed PCDs would share the same view:

'I would think that most PCDs would not be too keen to do this. Like I said for dentists, I would think that they would want the time treating patients, you know scaling and polishing.' (Kevin, 17.02.03)

\section{Competence}

Most participants did not feel adequately trained to undertake health interventions. They particularly expressed a lack of confidence in their communication skills:

'I wasn't confident in my ability to basically communicate the message properly.' (John, 28.11.02)

Advice on alcohol consumption was perceived to be difficult, especially by those with a disease focus:

'They might think it was prying and not actually something that is anything to do with their mouth and teeth - which is what they expect a dentist to be asking about.' (Kevin, 17.02.03)

Most felt that PCDs would also need training though some felt that they might need less than dentists. One participant commented:

'I can imagine that they might be more confident about talking about some of these things',

which:

'...might be because they have got more training in these issues.' (Diane, 21.02.03)

\section{Effectiveness}

No participant raised the issue of effectiveness of health interventions until the researcher introduced it. Of note was that all of the discussion was anecdotal rather than evidence-based.

When asked their views on the likely effectiveness of oral and general health interventions, there was a range of responses, with most perceiving PCDs to be effective:

'The oral hygiene in my patients improved enormously thanks to the hygienists rather than to me.' (John, 28.11.02)

However there were more circumspect views:

'So many initiatives on $\mathrm{CHD}$ (coronary heart disease) in the past have failed because they have not motivated people to change their behaviour.' (Isabelle, 12.02.03)

One participant thought PCDs might influence patients less:

'I do wonder whether people take more notice if it comes from a dentist.' (Isabelle, 12.02.03)

\section{Resources}

Resources was the predominant theme and encompassed time and finance factors of dental practice. The fee-per-item payment system discouraged dentists undertaking work for which they could not claim a fee, whether they were health or disease-orientated, reflecting a compromise between business necessity and the desire to undertake more prevention to meet professional responsibilities.

'It's a fine balance where you don't want to overstep the mark and become unprofitable.' (Lance, 19.02.03)

Workload and time pressures compounded these financial issues:

'I would worry about the workload that we already have, I mean where would you find the time to do it?' (Diane, 21.02.03)

Many felt that dentists' involvement in health interventions would be a poor use of their time but many would have been happy for PCDs to be involved as 'loss-leaders'. However, many felt that PCDs had more time for prevention:

'To be honest they will take more time than I might because they have got much more time booked.' (Kevin, 17.02.03)

Others had reservations about the use of PCDs in health interventions:

'There are few enough of them, why would you want to allocate their time away from their trained skills?' (Laurence, 18.12.02)

\section{QUANTITATIVE RESULTS}

Of 199 questionnaires distributed, 84.9\% were returned. Three were not completed adequately leaving 83.4\% usable for the analysis. Of the principals who responded, $87.9 \%$ were male. The mean length of time since qualification was 21.7 years (range 1.5 to 43 years) and they worked a mean of 26.7 hours per week in the practice for which they responded. There was a mean of 1.60 other dentists per practice, working a mean of 30.4 hours per week. Forty-nine practices (29.5\%) were single-handed.

Of the 155 practices that responded to the question, $88.8 \%$ of their income was derived from the NHS (range 0 to 100\%).

\section{Principal dentists' views on the relevance of the health interventions}

The proportions of dentists $(n=164)$ who thought that the public health interventions had at least some relevance to their practice was as follows: smoking prevention (93.9\%); smoking cessation (92.1\%); alcohol consumption advice (79.9\%); dietary advice (88.4\%); skin cancer prevention (66.5\%); advice physical exercise (35.3\%); and blood pressure monitoring (51.2\%). 
Principal dentists' frequency of involvement in health interventions (Table 1)

Apart from advice on prevention of skin cancer, physical activity and blood pressure monitoring, most dentists reported undertaking health interventions at least 'occasionally' (Table 1). Relatively few described their involvement in any intervention as 'often' or 'everyday'. Only $11.6 \%$ reported providing advice on alcohol consumption 'often' or 'everyday'.

\section{Views of principal dentists of the main barriers to dentists' and PCDs' involvement in health interventions (Table 2)}

The most frequently reported barriers to dentists and PCDs undertaking health interventions were 'insufficient funding' and 'poor use of time'. Significantly fewer dentists $(\mathrm{p}<0.05)$ perceived 'poor use of time' and 'lack of training/knowledge' as barriers for PCDs than they did for dentists.

Significantly fewer $(\mathrm{p}<0.05)$ reported 'Unlikely to be effective' as barriers for PCDs than for dentists for prevention of smoking/tobacco use, advice on alcohol consumption and advice on physical exercise. 'Unlikely to be effective' and 'likely to alienate patients' were reported most frequently for both dentists and PCDs for advice on alcohol consumption.

\section{PCDs undertaking health interventions in dental practice}

If the barriers identified in Table 2 were addressed, the proportion of dentists $(\mathrm{n}=166)$ who agreed that appropriately trained PCDs could undertake health interventions were as follows: smoking prevention (74.2\%); smoking cessation (74.8\%); advice on alcohol consumption (64.5\%); advice on diet/calorie intake (74.7\%); advice on skin cancer prevention (52.4\%); advice on physical exercise (46.4\%); blood pressure monitoring (57.9\%).

\section{Responses to second and third mailings of the questionnaire}

A separate analysis of data from the second and third mailings revealed that dentists' and practices' characteristics were similar to those of the first. The attitudinal data were also comparable.

\section{DISCUSSION}

This study investigated factors that might influence dental teams' involvement in general health promotion through provision of public health interventions. It is the first study to use a mixedmethod approach in this area of research and the first to investigate dentists' views about many of these interventions as well as the involvement of PCDs. Most dentists would be willing to employ trained PCDs to deliver a range of health interventions if barriers are removed. It appears there is a real willingness to expand the dental teams' remit through using PCDs in a public health role.

\section{Health-disease orientation of dentists}

Dentists with a health focus appeared more likely to support a preventive approach and to have a broader view of the role of the dental practice. This included a perception that patients would be happy that dental practices started to take an interest in their general health. They supported the use of PCDs, often citing the benefits of skill mix. They also perceived that they would be keen and able, having received necessary training, to extend their role to undertake health interventions. In contrast, disease-focused dentists tended toward a traditional, specific remit of the dental practice with less enthusiasm toward prevention. They had a positive view of PCDs but this often emphasised efficient treatment delivery.

This concept of a spectrum of health-disease orientation among dentists complements earlier research that suggested a typology of dentists' orientation as: ${ }^{38}$ altruistic; business orientated; and technically orientated. Disease-focused dentists emphasised treatment intervention which often reflected their enjoyment of the technical aspects of dentistry. However, our data suggest the typology is overly simplistic; all participants had elements of altruism, business and technical orientation but to varying degrees. For example, they all referred to the business implications of involvement in health interventions, however, its importance seemed to be related to their health-disease orientation.

Being able to define health is central to health promotion. Although the original WHO (1946) ${ }^{39}$ definition of health as: ' $a$

Table 2 Views of 166 principal dentists on the barriers to dentists and PCDs undertaking health interventions

\begin{tabular}{|c|c|c|c|c|c|c|c|c|c|c|}
\hline & \multicolumn{2}{|c|}{$\begin{array}{l}\text { Poor use of time } \\
\%\end{array}$} & \multicolumn{2}{|c|}{$\begin{array}{l}\text { Lack of training/ } \\
\text { knowledge } \\
\%\end{array}$} & \multicolumn{2}{|c|}{$\begin{array}{l}\text { Insufficient funding } \\
\%\end{array}$} & \multicolumn{2}{|c|}{$\begin{array}{l}\text { Unlikely to be } \\
\text { effective } \\
\%\end{array}$} & \multicolumn{2}{|c|}{$\begin{array}{l}\text { Likely to alienate } \\
\text { patients } \\
\%\end{array}$} \\
\hline & Dentists & PCDs & Dentists & PCDs & Dentists & PCDs & Dentists & PCDs & Dentists & PCDs \\
\hline $\begin{array}{l}\text { Prevention of smoking/ } \\
\text { tobacco use }\end{array}$ & $39.8^{*}$ & 20.5 & $22.9^{*}$ & 13.3 & 68.7 & 72.3 & $32.5^{*}$ & 27.7 & 23.5 & 21.1 \\
\hline Smoking cessation advice & $38.0^{*}$ & 19.3 & $29.5^{*}$ & 9.6 & 66.9 & 68.7 & 30.7 & 24.1 & 25.9 & 21.1 \\
\hline Advice on alcohol consumption & $49.4^{*}$ & 23.5 & $27.7^{*}$ & 10.2 & 68.1 & 65.7 & $41.6^{*}$ & 28.9 & 36.7 & 29.5 \\
\hline Advice on diet/calorie intake & $30.7^{*}$ & 16.9 & $22.3^{*}$ & 7.8 & 62.7 & 62.7 & 21.1 & 17.5 & 16.3 & 13.3 \\
\hline $\begin{array}{l}\text { Advice on prevention of } \\
\text { skin cancer }\end{array}$ & $45.2^{*}$ & 27.1 & $31.3^{*}$ & 12.0 & 62.0 & 64.5 & 26.5 & 20.5 & 13.9 & 12.7 \\
\hline Advice on physical exercise & $54.8^{*}$ & 34.9 & $32.5^{*}$ & 11.4 & 59.0 & 65.2 & $36.1^{*}$ & 23.5 & 28.9 & 22.9 \\
\hline Blood pressure monitoring & $48.2^{*}$ & 27.1 & $35.5^{*}$ & 12.1 & 63.3 & 63.9 & 19.4 & 15.7 & 15.7 & 12.7 \\
\hline
\end{tabular}


complete state of physical, mental and social well-being and not merely the absence of disease and infirmity' has been criticised, it clarified the distinction between disease and health. Historically, oral health services, and undergraduate teaching, have emphasised eradication of disease, rather than fostering well-being. This notion of well-being as being synonymous with health is emphasised in modern health promotion, most notably the Ottawa Charter. ${ }^{40}$ The provision of a clear definition of health as a psychosocial state, encompassing feelings, behaviours and ultimately quality of life ${ }^{41}$ as part of dental training, is essential for an increased emphasis on prevention to occur. This research suggests that dentists with a psychosocial, functional view of health do treat patients more holistically and with a greater emphasis on prevention. As this is one of the main aims of the changes to primary dental services in England, there are clearly important undergraduate education and continuing professional development issues to address if this aim is to be met.

\section{Dentists' views on public health interventions}

Apart from advice on physical exercise and blood pressure monitoring, the qualitative and quantitative parts of this study indicate that the health interventions are considered to be broadly relevant to dental practice. However, levels of involvement in all health interventions were lower than might be expected given these views (Table 1). These findings are compatible with existing data on smoking cessation, alcohol counselling and blood pressure monitoring. ${ }^{9-15}$

For example, $21.2 \%$ of responders in a Scottish study felt dentists had no role to play in smoking cessation. ${ }^{9}$ In this study $7.9 \%$ felt smoking cessation advice was irrelevant to their practice. It is disappointing that a few dentists still feel smoking cessation is irrelevant to dentistry. These findings suggest that local and national efforts to encourage dentists' involvement in smoking cessation have had limited effect. Given alcohol's well-recognised aetiological role in oral cancer, ${ }^{42-44}$ it is also surprising that $20.1 \%$ felt it was irrelevant to their practice and 39.6\% never provided advice on consumption. Reported levels of involvement in blood pressure measurement were similar to the only other UK study ${ }^{15}$ but contrast with US data where only $14.2 \%$ of dentists in the US had never been involved. ${ }^{45}$

\section{Barriers to dentists' involvement in public health interventions}

As well as a dentists' health-disease orientation, other barriers to dental involvement in this work related to The structure of dental practice. Barriers identified largely reflected the inflexibility of the current GDS and informed the content of the questionnaire.

The most commonly reported barriers were 'insufficient funding' and 'poor use of time' (Table 2). This concurs with previous research on smoking cessation. ${ }^{7}$ Given the fee-per-item payment system, the high treatment need in the area and workforce shortage this is unsurprising. Some have recommended paying fees for health interventions ${ }^{9}$ however, such an approach was ineffective in a pilot involving GDPs referring to a smoking cessation service in Sheffield. ${ }^{46}$ Local commissioning of services in England ${ }^{47}$ may address some financial barriers. However, any initiative to increase involvement in interventions may fail unless workforce shortages are addressed.

It is surprising that 'lack of training/knowledge' and 'unlikely to be effective' were not cited more often as barriers to involvement, given the lack of evidence of effectiveness and the limited training of most dentists in this work. Although participants in the qualitative study frequently cited a lack of training as a barrier to involvement, they rarely referred to effectiveness without being prompted, and when they did the evidence was largely anecdotal. In part this may reflect a lack of familiarity with the concept of evidence-based dentistry, as has been reported previously. ${ }^{48}$
Interestingly, many dentists, when interviewed, felt advice on alcohol consumption would be ineffective and would alienate patients - a finding which triangulates with our survey and a previous study. ${ }^{12}$ This may reflect the social acceptance of alcohol consumption, and dentists may feel hypocritical providing advice if they drink more than moderately.

\section{PCDs' involvement in public health interventions}

This is the first study to have investigated dentists' views on PCDs delivering a range of health interventions. An earlier study ${ }^{9}$ found that approximately two thirds of dentists felt PCDs had a role in smoking cessation, compared with $72.9 \%$ in this study broadly agreeing that they could be trained to do so. Cumulatively these data indicate high regard for PCDs' capabilities.

Although 'insufficient funding' and 'poor use of time' were still seen as the main barrier to PCDs' involvement, fewer dentists felt the latter was a barrier for PCDs for all seven interventions (Table 2). The qualitative data suggest that dentists perceive PCDs as less time-pressured, probably as most are paid on either a salary or sessional basis, and therefore dentists are happier to delegate this work to them. Many participants also supported the development of skill-mix within dental practice, which would encourage delegation.

Fewer dentists felt 'lack of training/knowledge' to be a barrier for PCDs than dentists in delivering health interventions (Table 2). UK hygiene and therapy students receive counselling training for dietary prevention of caries and smoking cessation in line with GDC guidance. ${ }^{49}$ Having received pre-qualification training, PCDs are more likely to be involved than those who have not, ${ }^{50,51}$ and more than dentists who receive similar training. ${ }^{51,52}$ These findings might explain dentists' greater confidence in PCDs to be effective without alienating patients by communicating messages in a sensitive manner. This view is supported by our qualitative data and suggests that training may help if health interventions are to be introduced to dental practice. ${ }^{53}$

\section{CONCLUDING DISCUSSION}

Given the workload of dentists and chronic disease prevalence in the UK, the use of PCDs to deliver health interventions seems sensible. However it is unclear whether the recent expansion of PCD training could meet this demand. Also it is essential that PCDs' remuneration encourages them to remain within the NHS - in some areas $80 \%$ of dental hygienists work exclusively privately. ${ }^{54}$ Local commissioning could provide opportunities to recruit more PCDs and remunerate them appropriately. ${ }^{55}$

The Ottawa Charter ${ }^{56}$ proposed re-orientating health services as a key element of health promotion. The qualitative data suggest that the orientation of dental practices in the UK is governed by whether the practice principal sees achieving health or treating disease as their main focus together with structural aspects of the GDS. Measures outlined in Options for change ${ }^{5}$ and the introduction of local commissioning in England could reduce structural barriers. For example, the removal of fee-per-item remuneration, increased emphasis on prevention, more use of skill-mix and enhanced integration into the NHS will all have re-orientating effects. However, it is essential that Primary Care Trusts and the Government are sensitive to the fact that dentists with a traditional disease focus may be resistant to expanding their role to these areas. Crucially, dentists must be helped to modify their outlook toward achieving health rather than treating disease if they are to be involved in this work and if the aims of Options for change are to be met. This has implications for the selection process for dental schools, undergraduate and postgraduate education.

As always, these data should be interpreted with care. However the response rate to the survey $(83.4 \%)$ is considerably higher than average, ${ }^{57}$ minimising sampling error. Also, analysis of the 
responses to the second and third mailings found respondent characteristics and attitudinal data were comparable, suggesting minimal non-response bias. Furthermore the qualitative and quantitative data broadly corroborated each other. However, the extent to which these findings can be generalised to other regions of the UK will also depend on logical inference as South Yorkshire has characteristics that may distinguish it from some areas. For example, the area contains a dental school where many of the dentists trained. Furthermore participants' attitudes to PCDs may be related to the expansion of PCD training programmes at that school.

In conclusion, although dentists' views on, and their involvement in, public health interventions varied considerably, there is a willingness to expand their team's role in this activity. Most principals perceived that most of the seven interventions were relevant to their practice and agreed that trained PCDs could undertake this work if barriers identified in the qualitative part of the study were addressed.

The authors wish to thank all dentists who participated in this survey. The authors also extend thanks to Joanne Johnson for administrative support and to Barry Gibson and Zoe Marshman for commenting on drafts of this report.

1. Saving lives: our healthier nation. London: Department of Health, 1999

2. Modernising NHS dentistry; implementing the plan. London: Department of Health, 2000.

3. Grabauskas V. Integrated programme for community health in noncommunicable disease (Interhealth). In Leparski $\mathrm{E}(\mathrm{Ed})$ The prevention of non-communicable diseases: experiences and prospects. pp 285-310. Copenhagen: WHO Regional Office for Europe, 1987.

4. World Health Organisation. Global strategy for the prevention and control of noncommunicable diseases. Geneva: WHO, 2000.

5. NHS Dentistry: Options for change. London: Department of Health, 2002.

6. Wanless Report. Securing good health for the whole population. London: HM Treasury, 2004

7. Choosing health: Making healthy choices easier. London: Department of Health, 2004.

8. Robinson P G, Dyer T A. General health promotion in general dental practice - The involvement of the dental team. Part 1: A review of the evidence of effectiveness of brief public health interventions. Br Dent J 2006; 200: 679-685.

9. Chestnutt | G, Binnie V I. Smoking cessation counselling - a role for the dental profession? BrDent J 1995; 179: 411-415

10. John J H, Yudkin, P, Murphy $M$, et al. Smoking cessation interventions for denta patients - attitudes and reported practices of dentists in the Oxford region. BrDent J 1997: 183: 359-364.

11. John J H, Thomas D, Richards D. Smoking interventions in the Oxford region: changes in dentists' attitudes and reported practice 1996-2001. Br Dent J 2003 195: $270-275$

12. McCann M F, Macpherson L M D et al. A survey of Scottish primary care dental practitioners on cancer -related practice and training requirements. Comm Dent Health 2000; 17: 24-30.

13. Warnakulasuriya K A A S, Johnson N W. Dentists and oral cancer prevention in the UK: opinions, attitudes and practices to screening for mucosal lesions and to counselling patients on tobacco and alcohol use: baseline data from 1991. Oral Dis 1999 5: $10-14$.

14. Campbell H S, Macdonald J M. Tobacco counselling among Alberta dentists. J Can Dent Assoc 1994; 60: 218-226.

15. Greenwood M, Lowry R J. Should GDPs be checking blood pressure? Br Dent J 2002; 193: $273-275$

16. Chestnutt I G, Binnie V I. Training in the provision of smoking cessation advice in United Kingdom dental schools and schools of hygiene. J Inst Health Ed 1996; 34: 109-111.

17. Newton J T, Palmer R M. The role of the dental team in the promotion of smoking cessation. Br Dent J 1997; 182: 353-355.

18. Smith $S E$, Warnakulasuriya $K A$ A S, Feyerabend $C$ et al. A smoking cessation programme conducted through dental practices in the UK. Br Dent J 1998; 185: 299-303.

19. Chestnutt I G. What should we do about people who smoke? Dent Update 1999; 26: 227-231.

20. Watt $R$, Robinson M. Helping smokers to stop: a guide for the dental team. London: Health Education Authority, 1999.

21. Watt R, Daly B, Kay E J. Prevention. Part 1: Smoking cessation advice within the general dental practice. Br Dent J 2003; 194: 665-668
22. Watt $R$ G, Johnson N W, Warnakulasuriya K A A S. Action on smoking - opportunities for the dental team. Br Dent J 2000; 189: 357-360.

23. Beaglehole R H, Watt R. Helping smokers to stop: a guide for the dental team. London: Health Development Agency, 2004.

24. Barker J B, Williams K B, Taylor T S, Barker, B F. Practice behaviours of alumni trained as students in tobacco use cessation interventions. J Dent Hyg 2001; 75: 165-169.

25. Fried J L, Rubinstein L. Dental hygienists' anti-tobacco role: educational perspectives. J Dent Ed 1989; 53: 712-717.

26. Boyd LD, Dwyer J T. Guidelines for nutritional screening, assessment, and intervention in the dental office. J Dent Hyg 1998; 72:31-43.

27. Ratcliff Davis J, Stegeman C A. The dental hygienist's guide to nutritional care. Philadelphia, Pennsylvania: WB Saunders Company, 1998.

28. Daniel S J, Harfst S A. Mosby's dental hygiene. Concepts, cases, competencies. St Louis, Missouri: Mosby, 2002.

29. Forrest J L, Horowitz A M, Schmuely Y. Dental hygienists' knowledge, opinions and practice related to oral and pharyngeal cancer risk assessment. J Dent Hyg 2001; 75: 271-281.

30. Syme SE, Drury TF, Horowitz A M. Maryland dental hygienists' knowledge and opinions of oral cancer risk factors and diagnostic procedures. Oral Dis 2001; 7: 177-184.

31. Mays N, Pope C. Qualitative research in health care. $2^{\text {nd }}$ edn. London: BMJ Publishing Group, 2000.

32. Burgess R D (Ed.) Field research: a sourcebook and field manual. London: Unwin Hyman, 1982.

33. Fielding J. Coding and managing data. In N Gilbert (Ed) Researching social life. London: Sage Publications, 1993.

34. Pfaffenberger B. Qualitative research methods, Series 14. Newbury Park, CA: Sage Publications, 1988.

35. Bowling A. Research methods in health: investigating health and health services. $2^{\text {nd }}$ edn. Buckingham, Philadelphia: Open University Press, 2002.

36. Dillman D. Mail and telephone surveys the total design method. New York: John Wiley and Sons, 1978.

37. Hoffman S C, Burke A E, Heizlsouer K J, Comstock G W. Controlled trial of the effect of length, incentives, and follow-up techniques on response to a mailed questionnaire. Am J Epidemiol 1998; 148: 1007-1011.

38. Calnan M, Silvester S, Manley G, Taylor-Gooby P. Doing business in the NHS: exploring dentists' decisions to practice in the public and private sector. Soc Health IIIness 2000; 22: $742-764$.

39. World Health Organization. Preamble to the Constitution of the World Health Organisation as adopted by the International Conference, New York 19-22 June, 1946.

40. World Health Organisation. Ottawa Charter for Health Promotion: An International Conference on Health Promotion. WHO Regional Office for Europe, Copenhagen, 1986.

41. Schou L, Locker D. Principles of oral health promotion. In C Pine (Ed) Community oral health. London: Wright, 1997.

42. Barra S, Franceschi S, Negri F et al. Type of alcoholic beverage and cancer of the ora cavity, pharynx, and oesophagus in an Italian area with high wine consumption. Int J Cancer 1990; 46: 1017-1020.

43. Llewellyn, J, Mitchell, R. Smoking, alcohol and oral cancer in southeast Scotland: a ten-year experience. Br J Oral Maxillofac Surg 1994; 32: 146-152.

44. Mashberg A, Boffetta P, Winkelman R, Garfinkel P. Tobacco smoking, alcohol drinking and cancer of the oral cavity and oropharynx among US veterans. Cancer 1993; 72: 1369-1375.

45. Ramprasaud $\mathrm{R}$, Carson $\mathrm{PH}$, Congdon $\mathrm{E} B$ et al. Dentists and blood pressure measurement: a survey of attitudes and practice. J Am Dent Assoc 1984; 108: 767-771.

46. Dyer T A. Evaluation of a payment scheme for dentists for referrals to the Sheffield Stop Smoking service. Sheffield South East Primary Care Trust, 2004.

47. Health and Social Care (Community Health Standards) Act. London: HMSO, 2003.

48. Iqbal A, Glenny A M. General dental practitioners' knowledge of and attitudes towards evidence-based practice. Br Dent J 2002: 192: 587-591.

49. Frameworks for the initial education of professionals complementary to dentistry (PCDs). Draft for consultation. General Dental Council, 2002.

50. Fried $J$ L, Rubinstein L. Dental hygienists' anti-tobacco role: educational perspectives. J Dent Ed 1989; 53: 712-717

51. Barker J B, Williams K B, Taylor T S, Barker B F. Practice behaviours of alumni trained as students in tobacco use cessation interventions. J Dent Hyg 2001; 75: 165-169.

52. Skegg J A. Dental programme for smoke-free promotion: attitudes and activities of dentists, hygienists and therapists at training and one year later. N Z Dent J 1999; 95: 55-57.

53. Commission of the European Communities' Advisory Committee on Training Dental Practitioners. Report and recommendations on training in oral cancer and precancer. Brussels: Commission of the European Communities in Brussels, 1988.

54. Sprod A, Boyles J. A survey of the training needs of the PCDs in the GDS. Br Dent J2003; 194: 389-397.

55. Dyer T A. Evaluation of the Barnsley therapist and remuneration Personal Dental Services pilot. Barnsley Primary Care Trust, 2004.

56. World Health Organisation. Ottawa Charter for Health Promotion: An International Conference on Health Promotion. Copenhagen: WHO Regional Office for Europe, 1986.

57. Tan R T, Burke F J T. Response rates to questionnaires mailed to dentists. Int Dent J 1997: 47:349-354 